\title{
DESAFIOS NA INCLUSÃO DIGITAL E ALTERNATIVAS ENCONTRADAS POR UNIVERSITÁRIOS AMAZÔNIDAS
}

\author{
THE CHALLENGES OF \\ DIGITAL INCLUSION AND THE \\ ALTERNATIVES USED BY \\ AMAZONIDAS STUDENTS
}

\author{
Danilo Teixeira Lima* \\ Ildete da Silva Falcão ${ }^{* *}$ \\ Maria da Penha de Andrade Abi Harb ${ }^{* * *}$
}

\section{RESUMO}

Atualmente, tem se intensificado as discussões sobre a importância da Inclusão Digital e alguns grupos deestudiosos, de diversas áreas de conhecimentos,têm unido esforços para integrar, por meio de atividades extensionistas, pessoas idosasà sociedade da informação. O Projeto IDIGETI (Inclusão Digital no GETI (Grupo de Educação na Terceira Idade)), do Campus de Castanhal da UFPA (Universidade Federal do Pará), localizado no nordeste paraense, promove, a partir de exposições teóricas e práticas, o saber sobre a utilização de tecnologias digitais, conhecimento preconizado no Estatuto que regulamenta os direitos deste público.Porém, existem fatores que obstruem a chegada dessa população ao ambiente virtual,e a presente pesquisa vem relatar as adversidades encontradas por um grupo de idosos da cidade de Castanhal,revelando, então, as problemáticas e alternativas encontradas para promover esse segmento social junto às TIC'S (Tecnologias de Informação e Comunicação).

Palavras-chave: Inclusão Digital; Pessoas Idosas; Obstáculos.

\section{ABSTRACT}

Currently, discussions on the importance of digital inclusion have intensified. Scholar groups, from different areas, have been joining efforts to integrate, through extension activities, older people to the information society. The IDIGETI Project (Digital Inclusion in GETI (Education Group in the Third Age)) is carried out in Campus Castanhal of Federal University of Pará (UFPA), located in the northeastern of Pará, Brazil. It provides information about the use of digital technologies through lectures and practices, which is required by the law that protects the rights of older people. However, there are factors that may inhibit older persons to access virtual environment. Thus, this study aims to show the difficulties faced by a group

\footnotetext{
* Aluno de graduação da Universidade Federal do Pará (UFPA), PA - Brasil. E-mail: danilosistema13@gmail.com

** Técnica em Assuntos Educacionais da Universidade Federal do Pará (UFPA), PA - Brasil. E-mail: ildetefalcao@gmail.com

*** Professora da Universidade Federal do Pará (UFPA), PA - Brasil. E:mail: mpenhaufpa@gmail.com
} 
of senior citizens of the city of Castanhal, revealing the issues and the alternatives found to provide them with the TICs (Information and Communication Technologies).

Keywords: Digital Inclusion; Older Persons; Obstacles.

\section{Introdução}

O surgimento das novas tecnologias (computadores, internet, smartphones, dentre outros) proporcionou à sociedade diversos benefícios, e essas ferramentas tornaram-se imprescindíveis aos vários segmentos sociais. "A penetração das tecnologias digitais está nos levando a um salto de evolução que acontece em velocidade vertiginosa sem precedentes na história da humanidade." (GABRIEL, 2003, s/p).

Souza (2003, p. 67), em seu livro Comunicação, Educação e Novas Tecnologias, sustenta que a maior vantagem obtida com o advento da internet é "sem dúvida a grande transformação social que ela tem proporcionado. Quando falamos em social nos referimos à troca do conhecimento entre as pessoas através da reciprocidade ou convivência”.

Silveira aponta que:

A informação penetrou na sociedade tal como a energia elétrica. Resultante da revolução industrial, reconfigurou a vida das cidades. O computador, ícone da nova revolução, ligado à rede, está alterando a relação das pessoas com o tempo e com o espaço [...] estamos falando de uma tecnologia que permite aumentar o armazenamento, o processamento e a análise de informaçóes, realizar bilhões relaçôes entre milhares de dados. (SILVEIRA, 2001, p. 15)

Juntamente ao crescente avanço de uma civilização dependente da utilização da internet e das TIC'S, várias pesquisas realizadas atualmente apontam para um inquestionável crescimento da população idosa, que não se restringe ao Brasil.

O crescimento da população idosa é um fato, e tal fato se justifica especialmente em função do avanço tecnológico presenciado em várias áreas de atuação humana, principalmente na área médica, e também devido a algumas alteraçóes sociais ocorridas em nossa sociedade, como, por exemplo, a redução da natalidade e aumento da expectativa de vida (NERI; CACHIONI, 1999, s/p).

O Estatuto do Idoso foi sancionado no dia 1 de outubro de 2003, Lei 10.741, e preconiza alguns direitos que esse público possui. No Art. 21. \10 "Os cursos especiais para idosos incluirão conteúdo relativo às técnicas de comunicação, computação e demais avanços tecnológicos, para a sua integração à vida moderna”. No entanto, segundo o IBGE (Instituto Brasileiro de Geografia e Estatística), apenas 12,6\% do segmento idoso brasileiro possui acesso à internet, de um número de 85,6 milhóes de usuários da rede mundial de computadores.

Por diversos fatores, alguns segmentos da sociedade foram restringidos da nova realidade de ampla utilização das novas tecnologias digitais e de mídias, por exemplo, parte da população de pessoas idosas. É considerado um cidadão digitalmente excluído quem não possui acesso às ferramentas tecnológicas atuais, como: computadores, celulares, caixas eletrônicos, eletrodomésticos, redes sociais, blogs, dentre outros. Esse cerceamento do manuseio das atuais tecnologias interfere diretamente no exercício de cidadania dessas pessoas, prejudicando suas relaçóes sociais, restringindooportunidades de atividades profissionais, dentre outras consequências que o mesmo acarreta.

Segundo Kachar (2003), essa geraçáo sente-se analfabeta diante das novas tecnologias, revelando dificuldades em entender a nova linguagem e em lidar com os avanços tecnológicos, até mesmo em 
questóes básicas com eletrodomésticos, celulares e os caixas eletrônicos instalados nos bancos.

A exclusão digital de pessoas velhas pode ser consequência de inúmeros fatores, dentre eles, os mais comuns são a falta de oportunidade do contato com o computador e as novas tecnologias, limitaçóes encontradas pela idade, por exemplo, baixa visão, fadigas, além da perda de parte da coordenação motora, o que dificulta a interaçáo desse público com os sensíveis hardwares, dentre outros.

Muitos estudiosos, professores e alunos de diversas áreas de conhecimento, por meio de momentos de discussão sobre o tema inclusão digital e atividades extensionistas, comaulas práticas e teóricas, vêm buscando atingir a diminuição dos elevados índices de exclusão tecnológica de pessoas idosas brasileiras.Porém, alguns fatores são imprescindíveis deserem observados no momento da promoção do conhecimento virtual, indicadores que de forma direta comprometem o progresso do aprendizado do público em questáo.

\section{Métodos}

A pesquisa foi realizada a partir da abordagem qualitativa com um coletivo de idosos do projeto IDIGETI, localizado no Campus Universitário da UFPA/Castanhal.Foi utilizado como instrumento de coleta de dados a entrevista semiestruturada, buscando investigar as problemáticas pertinentes no processo de transmissão do conhecimento tecnológico e as alternativas encontradas pelos universitários extensionistas desse projeto de inclusão, que por meio de exposição de conteúdos teóricos e práticos sobre utilização das novas ferramentas digitais, promovem inserção de velhos amazônidas no contexto virtual. Foi escolhida esta abordagem, pois segundo Neves (1996, p.1), "faz parte obtenção de dados descritivos mediante contato direto com a situação objeto de estudo".

A Faculdade de Computação do Campus de Castanhal, ao reconhecer a importância do cumprimento do Art. 21 do Estatuto do Idoso, e ao observar que neste Campus da UFPA não existia um projeto de inserção de pessoas idosas às ferramentas tecnológicas, apresentou à PROEX (Pró-Reitoria de Extensão da UFPA) a proposta de criação de atividades de cunho tecnológico, para serem trabalhadas com este público. A partir da aprovação do Projeto IDIGETI, vinculado ao Programa GETI, foram disponibilizados recursos para a efetivação dos processos de informatização da atual era digital aos alunos do Programa.

O GETI é um programa que, desde o ano de1999, oferece atividades voltadas à promoçáo de melhor qualidade de vida dos seus participantes, tanto pela alfabetizaçáo, quanto pelas atividades físicas, palestras informativas, cursos e momentos de lazer.

Pereira e Neves (2011, p.5) contribuem que:

Mais especificamente, no que concerne ao ensino das novas tecnologias a idosos, é necessário promover um ambiente de aprendizagem próprio para os indivíduos em questão, que passa pela criação de uma interação com a máquina de acordo com as suas necessidades e condiçôes físicas.

As aulas de informática desse curso acontecem às quartas-feiras, no horário da tarde, no laboratório de 40 micros do Campus de Castanhal, equipado com 2 (duas) centrais de ar condicionado, 1 (um) Datashow e internet. As atividades do Projeto 
iniciaram em maio de 2014. O curso já ofereceu 3 (três) turmas de informática básica e 3 (três) turmas de informática avançada, com 15 (quinze) alunos em média por turma. Objetivando um atendimento mais específico possível aos participantes, as turmas são formadas com poucos alunos. As aulas são ministradas por 01 (um) bolsista da Faculdade de Computação, acadêmico de Sistemas de Informação e por mais (duas) voluntárias acadêmicas de Pedagogia.

Os cursos de inclusão digital necessitam estar configurados de acordo com o perfil da população, com atendimento específico e com turmas pequenas e de mesma faixa etária, para promover o acesso e a capacitação do uso destes recursos tecnológicos. (KACHAR, 2010, p. 146)

O grupo de acadêmicos extensionistasdo Projeto insereuma parte do segmento de pessoas castanhalenses com idade superior a 50 anos na era de "compartilhamento instantâneo", apesar dos obstáculos impostos pela idade. O perfil dos participantes atendidos é de pessoas semialfabetizadas,do sexo feminino, habitantes da própria cidade que sedia o Campus Universitário provedor dasaçôes de inclusão digital.

Arenda dos alunos que participam dessas exposiçóes sobre as novas TIC'S varia entre 1 e 2 salários mínimos.Dificilmente, os matriculados nas aulas de informática possuem acesso a ferramentas tecnológicas em suas residências, sobretudo os microcomputadores.

Os conteúdos teóricos e práticos sobre a utilização das novas ferramentas tecnológicas são geralmente repassados aos alunos de micro a micro. "Quem ensina aprende ao ensinar e quem aprende ensina ao aprender." (FREIRE, 1996, p. 25). A partir desta troca de informação, os participantes têm setornado aptos a utilizarem novas e importantes ferramentas digitais, por exemplo, e-mail, Word, Excel e algumas redes sociais, além de desenvolverem a espertize de trabalho em grupo.O coletivo de universitários amazônidas participantes do Projeto pôde conhecer ainda mais sobre comportamento e habilidades das pessoas idosas, adquirindo experiências a partir dessa relação intergeracional.

$\mathrm{O}$ advento da tecnologia provê oportunidades para se tornar um aprendiz virtual, oferecendo a educação continuada, educação a distância, estimulação mental e bem-estar, possibilitando ao idoso estar mais integrado numa comunidade eletrônica ampla, colocando-o em contato com parentes e amigos, num ambiente de troca de informaçóes, reduzindo o isolamento por meio da experiência comunitária e auxiliando na construção de uma identidade como cidadão do mundo. (GRANDA; DUARTE, 2011, p. 7)

O curso promove a democratizaçáo do conhecimento digital, competência que está assegurada no Estatuto do Idoso. Alunos "conectados" à sociedade da informação possuem a oportunidade de buscar todos e quaisquer dados que lhes forem úteis.

\section{Resultados}

Ao realizar a investigação,forampercebidos alguns fatores que desafiam a proposta de inclusão tecnológica da pessoa idosa, descobertos por meio de entrevista e de análise das experiências no laboratório de informática. Foi detectado que a maior dificuldade encontrada para o progresso do aprendizado do aluno é com relação à saúde. "O processo de envelhecimento humano é acompanhado de mudança nos órgãos e sistemas 
do organismo, levando, com isso, a uma diminuição da reserva fisiológica, sendo essas mudanças inevitáveis." (SOUZA; IGLESIAS, 2002, p.81).

Rybash (1995) afirma que a maioria dos idosos enfrenta dificuldades ante as organizaçôes e interpretaçóes de informação ocasionadas por declínio na capacidade em reconhecer objetos. Por sua vez,Nunes (1999) diz que o processo de informaçóes pode ser subsídio para investigaçáo de aspectos cognitivos afetados com a idade, fazendo alusão à diminuição da atenção seletiva (responsável por compreender informações pertinentes) e atenção dividida (espertize deprocessamento de várias informaçóes no mesmo instante).

No entanto, atividades realizadas cotidianamente na internet proporcionam o aumentoda possibilidade de um acesso fácil e rápido, auxiliando na obtençáo de informaçóes sobre saúde e atividades físicas.A rede virtual é uma forma efetiva de incluir e atualizar o indivíduo. $\mathrm{O}$ uso regular da internet pode minimizar alguns fatores, como solidão, isolamento social e depressão por proporcionar a interaçáo do indivíduo com o meio social, através de amizades e informação (WHITE et al., 2002, p. 220).

A prática cotidiana da utilizaçáo de internet pode auxiliar na prevençấo do envelhecimento do cérebro, mantendo-o ativo e dinâmico. Várias pesquisas apontam que idosos que utilizam dessa ferramenta possuem melhor desenvolvimento cognitivo. Essas habilidades são muito importantes para a terceira idade em razáo do manuseio do computador. No processo de aprendizagem para interagir com a internet, são necessárias habilidades cognitivas e também motoras, o que traz um resultado positivo aos idosos (FREESE et.al., 2006, p. 236).

$\mathrm{Na}$ faixa etária a partir de 50 anos, é comum a apresentaçáo de declínio da audição, coordenação motora, visão e memória,no que consiste o desafio, em virtude de as ferramentas digitais conterem muitas funções, geralmente uma ligada à outra, o que requer boa memorização.

Os ministrantes das exposiçôes tecnológicasutilizaram-se de artifícios, como:iniciar as atividades por meio da ludicidade, objetivando criar prazer na execução das tarefas; utilizar as experiências de vida dos idosos para auxílio no desenvolvimento de material de apoio às aulas;usar os laboratórios com boa iluminação;usar datashow com slide, contendo textos em fontes grandes; observar o tamanho e a iluminaçáo do monitor;utilizar mais linguagens visuais quetextuais; falar de forma clara e objetiva, pausadamente, olhando nos rostos dos alunos, para quese pudessem compreender de forma simples o conteúdo e, assim, seevitar transtornos por conta de uma possível dificuldade auditiva. Os conteúdos repassados aos alunos são exaustivamente revisados, para assegurar que sejam bem assimilados, além deexercitar a memória. Kachar (2006, p. 296) afirma que se deve respeitar o ritmo de cada aluno; partir de situaçóes contextualizadas; efetuar repetiçấo das atividades; seguir etapas gradativas de aprendizagem.

"As alteraçóes emocionais advindas do processo de envelhecimento, de acordo com a Psicologia Atual, não resultam do ganhar idade." (FREITAS et al., 2002, p.226). O medo do náo aprendizado, sentimento não ocasionado pela idade, é um fator de grande incidência, masocorre pelo crédito que muitas pessoas conferem à sociedade, que prega estigmas de inexistência do aprender na velhice.

[...] em nossa cultura náo existe a idéia clara do ciclo da vida, recebemos umintenso treinamento para apenas a metade dela. Temos um "script" social muito claro a seguir até a idade de 50 anos. Quanto a isso náo há dúvida. Mas depois de ter cumprido os deveres, por assim dizer (estudar, 
se profissionalizar, casar, ter filhos, se aposentar, etc.), o que fazer com os próximos 10, 20, 30 ou 40 anos de existência? Onde está a orientação sobre essa etapa da vida humana que doravante será o tempo mais longo de nossa existência? (ARCURI, 2005, p. 14).

A autora nos instiga a uma reflexão sobre quebra de estereótipos impostos a todo momento pela sociedade sobre a velhice, pensamento que foi provocado nos próprios idosos, questionamentos que contribuíram para o rompimento de conceitos e que encorajam ao abandono de uma visão antiga, que resume o idoso a alguém que só se ocupa em recordar memórias. Incentiva ainda a prática de açóes socializadoras, que revelam à sociedade uma nova forma de respeitar a velhice, desafio árduo para uma sociedade altamente voltada ao consumo e à produção.

A insegurança da capacidade de aprendizado tornou muitos alunos dependentes do professor, sempre desejando o educador ao lado, mesmo quando sabiam o que era necessário para a realização das atividades propostas. Existe um grande receio da sala de aula, devido a experiências anteriores, como muitos participantes do curso que sofreram agressóes e desrespeitos, práticas comuns no passado, pela antiga metodologia usada por parte de alguns professores.

Foi trabalhado, a partir de vídeos e textos motivacionais, a autonomia e o protagonismo desse público, transmitindo-se mensagens e experiências que demonstram o verdadeiro potencial desse segmento. "Hoje, a pessoa idosa não vive mais, necessariamente, recolhida e recordando lembranças do passado, mas pode ser ativa e participativa." (KACHAR, 2001, s/p).A medida que iam resolvendo de forma independente as atividades, a autoconfiança era gerada nos participantes.

Os achados da pesquisa ratificam a existência de temor por partes dos matriculados no Projeto, de danificar o computador ou outras ferramentas tecnológicas utilizadas durante as aulas. A maioria dos idosos chegou ao curso insegurae em todo o momento chamava o tutor, acreditando ter lesado os equipamentos. Muitos participantes do Projeto náo possuíam um computador em casa, o que dificultava o processo de ensino, visto que é necessário haver prática. Apesar dessas dificuldades, evidenciou-se que, por meio das açóes dos universitários, o objetivo de integrar as pessoas idosas ao mundo globalizado foi alcançado de forma satisfatória.

\section{Conclusóes}

O processo de introdução do segmento idoso amazônida no novo contexto digital, em que a sociedade atual está inserida, atravessa por diversos desafios, como problemáticas ocasionadas pelas mudanças físicas, sociais, políticas, financeiras, dentre outras. Promover autonomia da pessoa idosa ante àsTIC'straz obstáculos, porém Freire,na obra Pedagogia da autonomia, estimula o docente a um posicionamento de perseverança, afirmando que barreiras existem para serem vencidas.

Gosto de ser gente porque, mesmo sabendo que as condiçóes materiais, econômicas, sociais e políticas, culturais e ideológicas em que nos achamos geram quase sempre barreiras de difícil superação para a nossa tarefa histórica de mudar o mundo, sei também que os obstáculos não se eternizam. (FREIRE, 1996,p.54) 
Deve-se compreender que o processo educacional não contém fórmulas prontas, cada discente possui peculiaridades, resultantes de um histórico de vida. No entanto, foi observado que, com a utilizaçáo de uma metodologia adequada às pessoas idosas, a inclusão digital pode ser alcançada com êxito.

É necessário considerar os diversos aspectos que conceituam a velhice, não limitando esta a estereótipos como doenças, aposentadoria e perda de capacidades cognitivas, motoras e sociais, pois dependerá da qualidade de hábitos vivenciada por cada indivíduo, visto que o envelhecimento é um processo natural, resultado de um processo de vida.(KACHAR, 2010, p. 145)

A inclusão digital na velhice ainda não é comum aos idosos brasileiros, sobretudo na Amazônia, local de funcionamento do Projeto IDIGETI.Ainda prevalecem estigmas que pregam a incapacidade da aprendizagem de pessoas idosas e ausências de políticas públicas efetivas à inclusão desta parcela da sociedade. A iniciativa de promover cursos de cunho tecnológico aos participantes do Programa GETI revelou resultados surpreendentes sobre a superação de limites, interesse, aceitação e participação dos idosos no Projeto, clarificando que, por meio de contatos com as Tecnologias de Informaçáo, também é alcançada a promoção de cidadania.

Pereira e Neves revelam, em suas pesquisas, resultados próximos aos encontrados pelo Projeto de Inclusão Digital oriundo da UFPA Castanhal:

[...] foi visível uma motivação acrescida por parte dos idosos, verificada através das expressóes sorridentes ao perceberem que, sozinhos, são capazes de utilizar a Internet e, sobretudo, de comunicar. Esta observação permitiu concluir que, para além de encurtar distâncias, o uso da Internet para fins comunicativos estreita relaçôes familiares, principalmente entre avós e netos. Ou seja, a Internet tem a capacidade de suavizar o fosso etário; avós e netos passam a utilizar a mesma linguagem, aproximando-se. (PEREIRA; NEVES, 2011, p. 19)

As pessoas idosas participantes do Projeto IDIGETI agregaram conhecimentos que lhes possibilitaram a superação de limites, que outrora jamais conseguiriam sem a utilização das tecnologias digitais enquanto ferramentas aliadas deste público, contribuindo significativamente para um novo processo formativo, bem como para a aquisição de conhecimentos e informaçóes com amigos e familiares.Isso evidenciando que a inclusão digital possibilita aos sujeitos sociais novas oportunidades.

\section{Referências}

ARCURI, I. G. Velhice: da gerontofobia ao desenvolvimento humano. In: CÔRTE, B.; MERCADANTE, E. F.; ARCURI, I. G. (Org.) Velhice, envelhecimento e complex(idade). São Paulo: Vetor, 2005, p. 35-56.

BRASIL. Estatuto do Idoso, 2003. Disponível em:<http://www.planalto.gov.br/ccivil_03/ leis/2003/l10.741.htm>. Acessoem: 18 dez. 2015.

FREESE, J.; RIVAS, S.; HARGITTAI, E. Cognitive ability and internet use among older adults. Poetics, v. 34, n. 4, p. 236-49, 2006. 
FREIRE, Paulo. Pedagogia da autonomia: saberes necessários à prática educativa. São Paulo: Paz e Terra, 1996.

FREITAS, M. C.; MARUYAMA, S. A.; FERREIRA, T. F.; MOTTA, A. M. A. Perspectivas das pesquisas em gerontologia e geriatria: revisão da literatura. Rev. Latino Americano de Enfermagem, $v$. 10, n.2, p. 2221-228, 2002.

GABRIEL. M. C. C. Educ@r - A (r)evolução digital na educação.São Paulo: Saraiva, 2013.

GRANDA, T.K.;DUARTE, A. B. S. Inclusão Digital na Terceira Idade: Identificando Contribuições e Lacunas. In: CONGRESSO BRASILEIRO DE BIBLIOTECONOMIA, DOCUMENTAÇÃO E CIÊNCIA DA INFORMAÇÃO, 24., 2011, Maceió. Anais... Maceió, 2011. p. 1-13.

IBGE. Disponível em: <http://www.ebc.com.br/tecnologia/2015/04/acesso-internetchega-494-da-populacao-brasileira>. Acesso em: 27 de ago. 2015.

KACHAR, V. A terceira idade e o computador: interação e produção num ambiente educacional interdisciplinar. Tese (Doutorado em Educação) - Pontifícia Universidade Católica de São Paulo - PUC, SãoPaulo,2001.

Terceira idade e informática: aprender revelando potencialidades. São Paulo: Cortez, 2003.

A terceira idade e a exploração do espaço virtual da internet. In: CÔRTE, B.; MERCADANTE, E.; GAETA, I. A. (Org.). Envelhecimento e Velhice: um guia para a vida. São Paulo: Vetor, 2006.p. 287-306.

. Envelhecimento e perspectivas de inclusão digital.Revista Kairós Gerontologia, São Paulo, v.13, n 2, p. 131-147, nov. 2010.

NEVES, J. L. Pesquisa Qualitativa: Características, usos e possibilidades. Caderno de pesquisa em administração, São Paulo, v.1, n. 3, 2.Sem. 1996.

NERI, A. L.; CACHIONI, M. Velhice bem-sucedida e educação.In: NERI, A. L.; DEBERT, G. G. (Org.). Velhice e sociedade. Campinas: Papirus, 1999.

NUNES, R. C. Metodologia para o ensino de informática para a terceira idade: aplicação no CEFET/SC. Dissertação (Mestrado em Engenharia de Produção) -Florianópolis, Universidade Federal de Santa Catarina, 1999.

PEREIRA, C.; NEVES, R.Os idosos na aquisição de competências TIC. Educação, Formação \& Tecnologias, v.4, n.2, p. 15-24, 2011. Disponível em: http://eft.educom.pt.Acessoem: 18 dez. 2015.

RYBASH, J. M. Adult and development and aging. Nova York: Brown \& Benchmark Publishers, 1995.

SILVEIRA, S. A. Exclusão Digital - a miséria na era da informação. São Paulo: Fundação Perseu Abramo, 2001. 
SOUZA, C. H. S. Comunicação, Educação e Novas Tecnologias. Rio de Janeiro:Ed. FAFIC, 2003.

SOUZA, J. A. G.; IGLESIAS, A. C. R. G.Trauma nos idosos.Rev. Assoc. Med. Bras., v. 48, n.1, p. 79-86, 2002.

WHITE, H. et al.A randomized controlled trial of the psychosocial impact of providing internet training and access to older adults.Aging Ment.Health, v. 6, n. 3, p. 213-21,2002. 